HortSCIENCE 25(3):344-346. 1990.

\title{
Genetic Resistance to Early Blight in Tomato Breeding Lines
}

\author{
Marisa Maiero' and Timothy $\mathbf{J}$ Ng \\ Department of Horticulture, University of Maryland, College Park, \\ MD 20742
}

\author{
Thomas H. Barksdale \\ Vegetable Laboratory, U. S. Department of Agriculture, Agricultural \\ Research Service, Beltsville, MD 20705
}

Additional index words. Lycopersicon esculentum, Alternaria solani, diallel, disease resistance, vegetable breeding

\begin{abstract}
Tomato (Lycopersicon esculentum Mill.) genotypes evaluated for early blight [Alternaria solani (Ellis \& Martin) Jones and Grout] resistance included five tolerant breeding lines, a susceptible cultivar, and seven hybrids among them. Three of the genotypes ('Castlejay', NC EBR-2, and 87B187) were crossed in a diallel mating design to estimate general combining ability and specific combining ability for the resistance trait. Parental, $F_{1}, F_{2}$, and backcross generations of the family Cl943 x 'Castlejay' were evaluated for resistance and included in generation mean analysis. Hybrid means for area under the disease progress curve were not significantly different from respective midparent values, indicating additive genetic control. Diallel and generation mean analyses also detected significant additive genetic effects. Epistasis was present in the Cl943 x 'Castlejay' family.
\end{abstract}

The fungus Alternaria solani (Ellis \& Martin) Jones and Grout causes the early blight disease of tomato during periods of heavy dew, rainfall, and humidity (Horsfall and Heuberger, 1942). Dark brown lesions with concentric rings are typical disease symptoms that first appear on older, mature leaves. Plants eventually become defoliated as the lesions expand. Stem, calyx, and fruit tissues are susceptible to A. solani as well (Barksdale and Stoner, 1977).

Sanitation, crop rotation, and protectant fungicidal sprays are the most common disease control measures, but these practices have limited success during humid, rainy seasons. The availability of resistant cultivars would reduce the need for routine fun-

Received for publication 25 Apr. 1989. Scientific Article no. A-4982. Contribution no. 8027 of the Maryland Agricultural Experiment Station (Dept. of Horticulture). We gratefully acknowledge the technical assistance of Carol Eichner and the computer support provided by the Univ. of Maryland Computer Science Center. The cost of publishing this paper was defrayed in part by the payment of page charges. Under postal regulations, this paper therefore must be hereby marked advertisement solely to indicate this fact.

'Present address: Dept. Agron. and Hort., New

Mexico State Univ., Las Cruces, NM 88003. gicide applications. Tomato breeding lines exhibiting field resistance to early blight have been developed, but most are low-yielding, late-maturing genotypes (Barksdale, 1971; Barksdale and Stoner, 1977; Gardner, 1988). Several Lycopersicon plant introductions have also been identified as resistant germplasm sources (Barksdale, 1969; Chen and Mutschler, 1988; Gardner, 1984; Locke, 1947; Martin and Hepperly, 1987).

Early blight resistance was determined to be quantitatively inherited for the breeding lines 71B2, Cl943 (Barksdale and Stoner, 1977), and NC EBR-1 (Nash and Gardner, 1988). In previous studies, we compared these three resistant breeding lines and several hybrids among them for response to an early blight epidemic (Maiero et al., 1989). Genetic analyses indicated that primarily additive factors were controlling the trait. In the current study, two new resistant breeding lines (87B187 and NC EBR-2) were used in addition to C1943, 71B2, and NC EBR-1. The objectives of this study were to compare several resistant lines and to estimate the genetic factors controlling the trait.

Six inbred tomato genotypes were used in this study. The genotypes 71B2, 87B187, C1943, NC EBR-1, and NC EBR-2 have some level of field resistance, while 'Castle- 
Table 1. Area under the disease progress curve values (AUDPC) for tomatoes inoculated with Alternaria solani in 1988 .

\begin{tabular}{|c|c|}
\hline Genotype & $\mathrm{AUDPC}^{2}$ \\
\hline Castlejay & $1532 \mathrm{a}$ \\
\hline Castlejay $\times$ NC EBR-2 & $1187 \mathrm{~b}$ \\
\hline Castlejay × 87B187 & $1106 \mathrm{bc}$ \\
\hline $87 \mathrm{~B} 187 \times$ Castlejay & $1059 \mathrm{bcd}$ \\
\hline NC EBR-2 $\times$ Castlejay & 1016 bcde \\
\hline C1943 x Castlejay & 918 bcde \\
\hline $87 \mathrm{~B} 187 \times \mathrm{NC}$ EBR-2 & 902 bcde \\
\hline NC EBR-1 & 850 cde \\
\hline 87B187 & 791 cde \\
\hline NC EBR-2 & 780 cde \\
\hline C1943 & $737 \mathrm{de}$ \\
\hline NC EBR-2 $2 \times 87 \mathrm{~B} 187$ & $707 \mathrm{e}$ \\
\hline 71B2 & $181 \mathrm{f}$ \\
\hline
\end{tabular}

${ }^{2}$ Mean separation in columns by Waller-Duncan k-ratio $t$ test, $5 \%$.

Table 2. General combining ability and specific combining ability variance components for tomato foliar resistance to Alternaria solani in a three-parent diallel mating system.

\begin{tabular}{lccc}
\hline \hline & \multicolumn{3}{c}{ AUDPC $^{z}$} \\
Source & df mean squares & F value \\
\hline Rep & 2 & 171,590 & $3.32^{\text {NS }}$ \\
Genotype & 8 & 194,862 & $3.77^{*}$ \\
GCA & 2 & 712,401 & $13.79^{* *}$ \\
SCA & 3 & 9,892 & $0.19^{\text {Ns }}$ \\
Reciprocal & 3 & 34,806 & $0.67^{\text {Ns }}$ \\
Error & 16 & 51,649 & \\
\hline
\end{tabular}

${ }^{2}$ Area under the disease progress curve.

Ns, $* * *$ Nonsignificant or significant at $P=0.05$ and 0.01 , respectively

Table 3. Generation means for early blight resistance in the tomato cross C1943 $\times$ 'Castlejay'.

\begin{tabular}{lrrr}
\hline \hline Generation & $\mathrm{n}$ & \multicolumn{1}{c}{ Mean } \\
\hline $\mathrm{P}_{1}($ Castlejay $)$ & 3 & $1531.7 \mathrm{a}$ & \multicolumn{1}{c}{ SE } \\
$\mathrm{BCP}_{1}$ & 75 & $1502.6 \mathrm{a}$ & 64.85 \\
$\mathrm{~F}_{1}$ & 3 & $918.3 \mathrm{bc}$ & 94.12 \\
$\mathrm{~F}_{2}$ & 142 & $1231.7 \mathrm{ab}$ & 43.96 \\
$\mathrm{BCP}_{2}$ & 73 & $1004.6 \mathrm{bc}$ & 58.42 \\
$\mathrm{P}_{2}($ C1943) & 3 & $736.7 \mathrm{c}$ & 145.93 \\
\hline
\end{tabular}

${ }^{2}$ Area under the disease progress curve.

Mean separation in columns by Waller-Duncan k-ratio t test, $5 \%$.

Table 4. Scaling tests for additive, dominance, and interaction parameters for resistance to early blight in the tomato cross C1943 x 'Castlejay'.

\begin{tabular}{ccr}
\hline \hline Test & Estimate & SE \\
\hline Joint 3-factor & & \\
$\mathrm{m}$ & 1335.49 & 76.80 \\
[d] & 454.24 & 66.99 \\
[h] & -256.76 & 140.27 \\
$\chi^{2}$ & $0.05-0.018 .41$ & \\
$P$ & $0.05-0.01$ & \\
Joint 6-factor & & \\
$\mathrm{m}$ & $1046.60^{* * *}$ & 269.04 \\
[d] & $397.50^{* * *}$ & 104.98 \\
[h] & 868.70 & 711.15 \\
[i] & 87.60 & 247.71 \\
[j] & 201.00 & 273.00 \\
[l] & $-997.00^{*}$ & 481.89 \\
****Scaling factors significantly different from \\
zero at $P=0.001$ and 0.05, respectively.
\end{tabular}

zero at $P=0.001$ and 0.05 , respectively. jay' is highly susceptible. The USDA breeding line 71B2 has the highest level of resistance among the genotypes evaluated (Barksdale and Stoner, 1977). C1943, developed by the Campbell Institute for Agricultural Research, has moderate early blight resistance (Barksdale and Stoner, 1977). The breeding lines NC EBR-1 and NC EBR-2 were released by the North Carolina Agricultural Research Service in 1988 (Gardner, 1988). NC EBR-1 and the USDA breeding line 87B187 have L. hirsutum parentage and moderate levels of resistance. NC EBR-1 derives resistance from P.I. 126445 and 87B187 from P.I. 390662. NC EBR-2 has moderate early blight resistance derived from C1943.

Three of the genotypes ('Castlejay', NC EBR-2, and 87B187) were crossed in a diallel mating design to estimate general combining ability (GCA) and specific combining ability (SCA) for the resistance trait. $\mathrm{F}_{1}, \mathrm{~F}_{2}$, and backcross generations of the cross $\mathrm{Cl} 943$ $x$ 'Castlejay' were evaluated for resistance and included in generation mean analysis.

The six parents, seven $\mathrm{F}_{1}, \mathrm{~F}_{2}$, and backcross generations were transplanted on 27 May 1988 into a Hatboro silt loam (fineloamy, mixed, nonacid, mesic typic fluvaquents soil) at the USDA Agricultural Research Center at Beltsville, Md. Plots were arranged in a randomized complete-block design with three replications and five plants per plot. The susceptible cultivar Pik-Red was planted for border rows, and two 'PikRed' plants surrounded each experimental plot to ensure uniform inoculum spread in the field. Each $\mathrm{F}_{2}$ and backcross generation had 10 plots per replication and five plots per replication, respectively. Commercial recommendations for fertilization and insect control were followed, but no fungicides were applied.

Ten A. solani isolates endemic to the eastern United States were used as inoculum. Six of the isolates were supplied by the USDA Vegetable Crops Laboratory, Beltsville, Md. The other four isolates were from two tomato fields used in 1987 for early blight studies at Beltsville and Salisbury, Md. Inoculum was prepared according to the methods used in these previous studies (Maiero et al., 1989). Spores from all 10 isolates were mixed with distilled water to produce 18 liters of spore suspension with 1000 spores/ml. Field inoculations were performed with a hand sprayer 3 to $4 \mathrm{hr}$ before darkness on 13 July, and percent defoliation of the plots was estimated on 9,23, and 31 Aug.

Data for each plot were converted to area under the disease progress curve (AUDPC) values and used in the analysis of variance for AUDPC (Shaner and Finney, 1977). Parental and hybrid mean separations and midparent-hybrid mean comparisons were calculated as described by Maiero et al. (1989). Parents, $F_{1}$ progeny, and reciprocal crosses were included in the diallel mating system and analyzed for GCA and SCA according to Griffing's (1956) Model 1 Method 1 procedure, where valid inferences can be made only for the experimental material used. Generation mean analysis and joint scaling tests for the $\mathrm{Cl} 943 \times$ 'Castlejay' family were performed according to Mather and Jinks (1982)

Analysis of variance of AUDPC data detected significant differences among the genotypes tested (data not shown). Mean separation of inbred and hybrid AUDPC values (Table 1) showed that 'Castlejay' and its hybrids were most susceptible to early blight, while the breeding line 71B2 was most resistant. The breeding lines C1943, NC EBR1, NC EBR-2, and 87B187 showed moderate levels of resistance.

Paired comparisons of midparent and hybrid means (data not shown) revealed no significant differences, indicating possible additive genetic control for the resistance trait. Reciprocal hybrids of the resistant lines NC EBR-2 and 87B187 were also resistant and not significantly different from the midparent value. This reaction differs from the resistant $\times$ resistant crosses of C1943 and 71B2 that were susceptible and significantly different from the midparent value in earlier studies (Maiero et al., 1989). C1943 and 71B2 appear to have one or more nonallelic, recessive resistance genes (Barksdale and Stoner, 1977). Possibly, C1943, NC EBR2 , and $87 \mathrm{~B} 187$ share common resistance genes different from 71B2.

Estimates of GCA, SCA, and reciprocal effects were obtained from diallel analysis for the three parents and six hybrids tested (Table 2). Hybrids included NC EBR-2 $\times$ 'Castlejay', 87B187 × 'Castlejay', and NC EBR-2 $\times 87 \mathrm{~B} 187$ and their three reciprocal crosses. The estimate for GCA was significant, whereas SCA and reciprocal estimates were not. GCA accounted for $91 \%$ of the total genotypic variation in the analysis, suggesting the importance of additive gene action in early blight resistance. The lack of significance for SCA denotes that a hybrid breeding program would have limited benefits with the genotypes studied.

GCA effects were calculated to be -114 , - 116, and 230 for NC EBR-2, 87B187, and 'Castlejay', respectively. A more negative GCA indicates greater early blight resistance, as with the breeding lines NC EBR-2 and 87B187. 'Castlejay' had a large GCA value related to its high degree of susceptibility. The relative performance of the three parents according to GCA values agreed with the ranking by AUDPC means; therefore, parental selection for a breeding program would be similar whether based on AUDPC phenotypes or GCA values.

AUDPC mean values for the family C1943 $\times$ 'Castlejay' are shown in Table 3 . The $F_{1}$ mean was not significantly different from $\mathrm{C} 1943$ or from the midparent value. The $\mathrm{F}_{2}$ generation mean was significantly different from $\mathrm{C} 1943$, but not from the $\mathrm{F}_{1}$ mean. The AUDPC mean for the backcross to the susceptible 'Castlejay' was not significantly different from 'Castlejay', and the backcross to the resistant parent C1943 was not significantly different from $\mathrm{C} 1943$, the $\mathrm{F}_{1}$, or the $\mathrm{F}_{2}$ generation means.

A simple additive-dominance model predicts equal $F_{1}$ and $F_{2}$ means midway between 
the parental means, and backcross generation means midway between $\mathrm{F}_{1}$ and respective parental values (Mather and Jinks, 1982). The C1943 × 'Castlejay' family does not clearly fit this model. A joint 3-factor scaling test (Mather and Jinks, 1982) to estimate the parameters $\mathrm{m}$ (midparent value), [d] (additive effects), and [h] (dominance effects) revealed that the data did not fit a simple additive-dominance model (Table 4). Epistasis was suspected to be present and a joint 6-factor model was therefore tested.

The joint 6-factor model estimates $\mathrm{m}$, [d], $[\mathrm{h}]$, and three epistatic interaction parameters, additive $\times$ additive [i], additive $\times$ dominance [j], and dominance $x$ dominance [1] (Mather and Jinks, 1982). The midparent value, additive parameter, and dominance $\times$ dominance interaction parameter were significant. These results emphasize that both additive and epistatic effects were involved in early blight resistance and agree with conclusions from previous studies (Nash and Gardner, 1988; Maiero et al., 1989).

The importance of additive genetic factors was repeatedly indicated by three genetic analyses (midparent-hybrid comparisons, diallel and generation mean analyses). Still, the severity of an early blight epidemic is influenced by environmental conditions and estimates of heritability are low to moderate (Nash and Gardner, 1988). Also, early fruit maturity is associated with susceptibility to early blight. This situation complicates evaluation of resistance and progress toward release of early maturing resistant cultivars. Of the resistant breeding lines evaluated, NC EBR-2 has the greatest potential for future breeding of a resistant commercial cultivar. NC EBR-2 has moderately early fruit maturity, resistance to Fusarium and Verticillium spp., and many desirable fruit characteristics, but was not released as a cultivar because of a rough blossom scar (Gardner, 1988). Recently, Chen and Mutschler (1988) were able to identify Lycopersicon accessions with moderately early maturity and good field resistance to early blight; however, these genotypes would require extensive breeding to reach horticultural acceptance.

\section{Literature Cited}

Barksdale, T.H. 1969. Resistance of tomato seedlings to early blight. Phytopathology 59:443446.

Barksdale, T.H. 1971. Field evaluation for tomato early blight resistance. Plant Dis. Rptr. 55:807809.

Barksdale, T.H. and A.K. Stoner. 1977. A study of the inheritance of tomato early blight resistance. Plant Dis. Rptr. 61:63-65.

Chen, Z.X. and M.A. Mutschler. 1988. Tolerance in tomato to early blight (Alternaria solani (Ell. and Martin) Sor.). Tomato Genetics Coop. Rpt. 38:13-15.

Gardner, R.G. 1984. Use of Lycopersicon hirsutum P.I. 126445 in breeding early blight-resistant tomatoes. HortScience 19:208.

Gardner, R.G. 1988. NC EBR-1 and NC EBR-2 early blight resistant tomato breeding lines. HortScience 23:779-780.

Griffing, B. 1956. Concept of general and specific combining ability in relation to diallel crossing systems. Austral. J. Biol. Sci. 9:463-493.

Horsfall, J.G. and J.W. Heuberger, 1942. Causes, effects and control of defoliation on tomatoes. Conn. Agr. Expt. Sta. Bul. 456:183-223.

Locke, S.B. 1947. Resistance to early blight and Septoria leaf blight in the genus Lycopersicon. Phytopathology 39:829-836.

Maiero, M., T.J Ng, and T.H. Barksdale. 1989. Combining ability estimates for early blight resistance in tomato. J. Amer. Soc. Hort. Sci. 114:118-121.

Martin, F.W. and P. Hepperly. 1987. Sources of resistance to early blight, Alternaria solani, and transfer to tomato, Lycopersicon esculentum. J. Agr. Univ. Puerto Rico 71:85-95.

Mather, K. and J.L. Jinks. 1982. Biometrical genetics. 3rd ed. Chapman and Hall. New York.

Nash, A.F. and R.G.Gardner. 1988: Heritability of tomato early blight resistance derived from Lycopersicon hirsutum P.I. 126445. J. Amer. Soc. Hort. Sci. 113:264-268.

Shaner, G. and R.E. Finney. 1977. The effect of nitrogen fertilization on the expression of slowmildewing resistance in 'Knox' wheat. Phytopathology 67:1051-1056. 